\title{
ИНСТИТУЦИОНАЛЬНАЯ ТУРБУЛЕНТНОСТЬ СИСТЕМЫ ГОСУДАРСТВЕННЫХ ЗАКУПОК В РОССИИ"
}

\author{
(C) 2019 Цыганков Сергей Сергеевич \\ кандидат экономических наук, преподаватель кафедры экономической теории \\ Южный федеральный университет, Россия, Ростов-на-Дону \\ e-mail: sscygankov@sfedu.ru
}

\section{(c) 2019 Наливайко Сергей Витальевич}

магистр экономики, магистр юриспруденции, заместитель начальника отдела размещения государственного заказа

Фонд «Инноваций и экономических технологий «Содействие - XXI век», Россия, Ростов-на-Дону e-mail: eco-sn@yandex.ru

\section{(c) 2019 Цыганкова Екатерина Мурадовна}

магистр экономики, аспирант

Южный федеральный университет, Россия, Ростов-на-Дону

e-mail: ekaterinagasanova@yandex.ru

В Российской Федерации создается уникальная система государственных закупок. С одной стороны, наблюдается практическая полная электронизация закупок, а с другой - доминирование торгового способа закупок, в котором победитель определяется только по цене - электронного аукциона. В статье исследуется одна из самых актуальных проблем государственных закупок, которая дефинируется как институциональная турбулентность Закона № 44-ФЗ и подзаконных нормативноправовых актов, а также ведомственных актов.

Ключевые слова: государственные закупки, институты, электронизация закупок, аукцион.

Электронные способы закупок известны в экономической науке снижением трансакционных издержек в первую очередь, однако стоит отметить, что процесс государственных закупок в Российской Федерации далек от полной автоматизации. При этом, электронный аукцион в Федеральном законе от 05.04.2013 № 44-Ф3 «О контрактной системе в сфере закупок товаров, работ, услуг для обеспечения государственных и муниципальных нужд» (далее - Закон № 44Ф3) имеет характеристики реверсивного аукциона: цена контракта, поданная участниками в ходе торгов снижается в зависимости от шага, выбранного участником в законодательно установленных рамках. С 2019 года в системе государственных закупок России началась полная электронизация рынка - способы закупок «запрос котировок», «открытый конкурс», «конкурс с ограниченным участием», «запрос предложений», проводимые в бумажной форме, фактически были упразднены. Самым важным достижением принятия законопроектов о переводе в электронный формат всех закупок товаров, работ, услуг является возможность перехода на следующий этап развития системы закупок - eе возможная цифровизация или диджитализация [1]. Здесь стоит отметить ряд институциональных проблем системы.

Согласно сводному аналитическому отчета мониторинга закупок за 2018 год, электронный аукцион по количеству закупок занимает 60\% всех способов закупок, в то время как по начальной (максимальной) цене контрактов (НМЦК) доля такого способа составила 68,7\%. Распределение количества извещений и НМЦК самых актуальных способов определения поставщика (подрядчика, исполнителя) приведено в таблице 1.

Исследование институциональных проблем в системе государственных закупок связано как с классическими институциональными проблемами, не раз охарактеризованными в экономической теории, так и практической вещественной реализацией процесса закупки.

\footnotetext{
" Статья подготовлена в рамках исполнения проекта РФФИ № 18-010-00871 «Разработка инструментария оценки и стимулирования качества публичных закупок: концептуальные основания и методические подходы».
} 
Таблица 1. статические данные проведения способов определения поставщика (подрядчика, исполнителя) в 2018 году [4].

\begin{tabular}{|l|c|c|}
\hline $\begin{array}{l}\text { Наименование способа определения поставщика } \\
\text { (подрядчика, исполнителя) }\end{array}$ & $\begin{array}{c}\text { Общее количество } \\
\text { извещений }\end{array}$ & НМЦК \\
\hline Открытый конкурс & 40613 & 604490088965 \\
\hline Открытый конкурс в электронной форме & 586 & 5103886283 \\
\hline Конкурс с ограниченным участием & 10632 & 364612193180 \\
\hline Конкурс с ограниченным участием в электронной форме & 93 & 2139196760 \\
\hline Электронный аукцион & 1955174 & 5663648385103 \\
\hline Запрос котировок & 397054 & 65244353203 \\
\hline Запрос котировок в электронной форме & 6728 & 1120937438 \\
\hline Запрос предложений & 9921 & 78354169564 \\
\hline Запрос предложений в электронной форме & 1367 & 64243964815 \\
\hline Закупка у единственного поставщика (подрядчика, исполнителя) & 752535 & 1122982059058 \\
\hline
\end{tabular}

Во-первых, с институциональной точки зрения, в самом Законе № 44-ФЗ и подзаконных нормативно-правовых актах практически не решается проблема принципал-агента, связанная с асимметрией информации на рынке госзакупок, в том числе, создания преимущественных условий в проведении закупок и картелизации закупок. К примеру, проблема обоснования НМЦК не только связана с перерасходом бюджетных средств или выбором метода обоснования, но и с заведомым общением заказчика с потенциальными участниками закупки. Сервис обоснования начальной максимальной цены контракта, предлагаемой на разных платформах, может учитывать различное количество параметров при подборе и автоматически на основе введенных позиций с различными фильтрами выдавать готовые результаты в течение нескольких секунд [2].

Второй проблемой является рентоориентированное поведение участников рынка госзакупок. Со стороны заказчика необходимо выделить фаворитизм относительно участников, со стороны участников «лоббирование» своих интересов по победе в закупке с минимальным падением, а также картелизацию многих сфер или недостаточную конкурентность самих процедур закупок. Кроме этого, проблема функционирования системы государственных закупок заключается в том, что отсутствует единый институциональный механизм определения эффективности закупки. Из-за этого отсутствует методология доходов и расходов государства от функционирования всей системы закупок. К примеру, оценки потерей государства при про- ведении госзакупок (в соответствии с Законом № 44-ФЗ составляют: рост во втором полугодии 2018 года - первом полугодии 2019 года относительно аналогичного предыдущего периода на 60,67\%, в количественном выражении 227,8 млрд. рублей (без учета уровня инфляции) [5]. Таким образом необходимо развивать таргетирование закупки по этапности и качеству. Определить эффективность не только ценой контракта и экономией бюджета, но и качеством запланированных показателей в закупке и достигнутых в ходе исполнения контракта. То есть, не должно быть ситуации, когда эффективной является закупка сугубо с максимальным снижением НМЦК, без учета качества исполнения заключенного контракта. Снижение цен недобросовестными поставщиками для получения контракта «любой ценой», как правило, приводят к нарушению сроков и/или поставки товаров низкого качества [3].

Одним из решений части проблем фаворитизма может являться полная автоматизация процесса закупки в части выбора победителя закупки независимым регулятором, создание автоматического алгоритма определении НМЦК, а также упрощение процедур закупок. Современные институты регулирования могут быть обогащены внедрением роботов и ботов в качестве перспективных систем интеллектуального анализа закупок [2]. Одними из самых ярких нововведений могли бы послужить введение «выражение согласия» на условия, отраженные в закупочной процедуре на все работы и услуги при подаче заявки и ограничение «сложной технической части» по закупкам на товары. 
Одним из решений проблем эффективности закупок может служить зависимость качества «у» (в баллах) от значимости каждого фактора «Х» в закупке. При этом, стоит предложить следующие факторы «Х» в закупке:

Х1 - НМЦК;

$\mathrm{X} 2$ - экономия\%

X3 - наличие в контракте пеней/неустоек

$\mathrm{X} 4-\%$ исполнения

Х5 - кол-во заявок

Х6 - наличие судебных дел

X7 - кол-во дополнительных соглашений, в том числе, изменяющих цену контракта

X8 - наличие обжалований в контрольном органе.

Анализ качества переменной «у» будет зависеть от разделения значимости («вклада») каждого фактора «Х» в итоговое качество закупки.

Следующей институциональной проблемой является неоднородность административной практики: контрольные органы различных субъектов Российской Федерации принимают отличные друг от друга решения по важнейшим вопросам функционирования контрактной системы. Кроме этого, позиция может меняться и внутри самого контрольного органа. Ярким примером такой неоднородности является вопрос оценки деловой репутации организации, являющимся законным способом оценки".

Однако в контрактной системе отсутствует институционально закрепленное описание показателей и порядка оценки такой деловой репутации. Это приводит к тому, что заказчики самостоятельно выбирают показатели и разрабатывают порядок оценки, которые характеризуют деловую репутацию. Соответственно схожий порядок оценки контрольным органом может быть признан объективным или субъективным, что влияет на продолжение или остановку всей закупки. Кроме этого, члены закупочных комиссий при оценке заявок могут использовать свои дискреционные полномочия и право доступа к конфиденциальной информации, чтобы дать преференции одному из участников закупок в соответствии с собственными интересами [7].

Проблема турбулентности институциональной среды закупок состоит в кардинальном изменении вектора системы государственных закупок Российской Федерации, характеризующаяся изменением или отменой институтов закупок (планирование, способы определения поставщика, подрядчика, исполнителя, изменение описания объекта закупок, включая введение каталога товаров, работ, услуг, заключение контракта, инфорсмент контрактов). Нормативноправовых актов в контрактной системе в актуальной редакции насчитывается не менее 130, а за пять лет действия контрактной системы их было более 270 [6]. Множество актов было отменено, или они утратили силу.

Такую турбулентность системы государственных закупок можно представить через изменения Закона № 44-ФЗ (таблица 2).

Как показывают данные Таблицы 2 с момента принятия Закона № 44-ФЗ до конца 2019 г. было принято 60 различных редакций. При этом, если в первый год действия Закона № 44-Ф3 (с 1 по 16 редакцию) изменения касались добавления важных деталей закупочной деятельности и исправлению стартовых ошибок системы госзакупок, то период 2018-2020 г.г. (с 40 редакции) ознаменовался серьезными институциональными преобразованиями. Переход к общей электронизации закрыл несколько этапов институциональных преобразований системы закупок и ознаменовался фактически невозможностью выбора порядка проведения закупки. Здесь также нужно отметить расширение типизации закупочного процесса: широкое внедрение типовых контрактов, возможность разработки типовой документации, а также типовой формы заявки. Стоит отметить постепенное сокращение времени процедуры закупки и увеличение возможностей проведения неконкурентных закупок. Кроме этого, с точки зрения эффективности проведения государственных закупок необходимо отметить, что несколько раз успела поменяться норма по согласованию заключения контракта с контрольным органом в случае несостоявшейся закупки. Фактически поменялась каждая стадия закупки и планирования закупки: от извещений до исполнения контрактов и отчетов по их исполнению, отменены планы закупок, расширены правила контроля закупок, в т.ч. ведомственные.

\footnotetext{
* В соответствии с пп. д) п. 27 Постановления от 28 ноября 2013 г. № 1085 «Об утверждении правил оценки заявок, окончательных предложений участников закупки товаров, работ, услуг для обеспечения государственных и муниципальных нужд».
} 
Таблица 2. Анализ изменений Закона № 44-ФЗ в 2014-2015 гг и с 2018 года

\begin{tabular}{|c|c|c|}
\hline $\begin{array}{l}\text { Номер } \\
\text { редак- } \\
\text { ции }\end{array}$ & Начало действия & Краткое описание изменений \\
\hline 1 & - & Редакция до вступления в силу Закона \\
\hline 2 & - & Редакция до вступления в силу Закона \\
\hline 3 & 1 января 2014 г. & Редакция на дату вступления в силу Закона \\
\hline 4 & 4 июня 2014 г. & $\begin{array}{l}\text { Внедрение проектно-сметного метода для обоснования НМЦК, изменение пра- } \\
\text { вил закупки у субъектов малого предпринимательства и социально ориентиро- } \\
\text { ванных НКО, изменение единых требований к участникам закупки, изменение } \\
\text { требований к банковской гарантии, изменения к требованиям содержания } \\
\text { извещений о конкурентных закупках, изменение сроков продления процеду- } \\
\text { ры при внесении изменений в документацию об аукционе, новые основания } \\
\text { признания аукциона несостоявшимся, новый порядок осуществления закупок у } \\
\text { единственного поставщика }\end{array}$ \\
\hline 5 & 22 июля 2014 г. & $\begin{array}{l}\text { Добавление новых оснований закупки у единственного поставщика (подрядчи- } \\
\text { ка, исполнителя) }\end{array}$ \\
\hline 6 & 13 декабря 2014 г. & $\begin{array}{l}\text { Добавление новых оснований закупки у единственного поставщика (подрядчи- } \\
\text { ка, исполнителя) }\end{array}$ \\
\hline 7 & 31 декабря 2014 г. & $\begin{array}{l}\text { Отмена согласования заключения контракта в случае признания аукцио- } \\
\text { на несостоявшимся, новое основание закупки у единственного поставщика } \\
\text { (подрядчика, исполнителя), новые основания изменений условий контракта, в } \\
\text { составе заявки теперь указывается «страна происхождения товара», а не «место } \\
\text { происхождения товара или наименование производителя товара», добавление } \\
\text { возможности отстранять участника аукциона на любом этапе его проведения, в } \\
\text { случае выявления недостоверной информации }\end{array}$ \\
\hline 8 & 1 января 2015 г. & $\begin{array}{l}\text { Добавление новых оснований закупки у единственного поставщика (подрядчи- } \\
\text { ка, исполнителя) }\end{array}$ \\
\hline 9 & 9 марта 2015 г. & $\begin{array}{l}\text { Уточнение правил обоснования НМЦК и оснований закупки у единственного } \\
\text { поставщика (подрядчика, исполнителя) }\end{array}$ \\
\hline 10 & 1 апреля 2015 г. & Изменение требований к банковским гарантиям \\
\hline 11 & 7 апреля 2015 г. & Обязанность заявку заверять печатью только при ее наличии \\
\hline 12 & 1 июля 2015 г. & $\begin{array}{l}\text { Право Правительства РФ установить дополнительные требования при закупке } \\
\text { аудиторских и консультационных услуг }\end{array}$ \\
\hline 13 & 13 июля 2015 г. & $\begin{array}{l}\text { Включение корпорации «Роскосмос» в текст закона, добавлены особенности } \\
\text { исполнения контракта на оказание услуг по предоставлению кредита }\end{array}$ \\
\hline 14 & 14 июля 2015 г. & Уточнение правил обоснования НМЦК \\
\hline 15 & 13 августа 2015 г. & $\begin{array}{l}\text { Изменение определения «участник закупки», изменение требований к участни- } \\
\text { кам закупки (организации, зарегистрированные в офшорах не могут считаться } \\
\text { такими участниками), Уточнение правил обоснования НМЦК и оснований } \\
\text { закупки у единственного поставщика (подрядчика, исполнителя) }\end{array}$ \\
\hline 16 & 15 сентября 2015 г. & Изменение сферы регулирования закона \\
\hline \multicolumn{3}{|r|}{$\ldots$} \\
\hline 40 & 11 января 2018 г. & $\begin{array}{l}\text { Изменение правил описания объекта закупки, порядка ведения реестра недо- } \\
\text { бросовестных поставщиков, изменение оснований закупки у единственного } \\
\text { поставщика (подрядчика, исполнителя) }\end{array}$ \\
\hline 41 & 4 мая 2018 г. & $\begin{array}{l}\text { Изменение заключительных положений закона, связанных со списанием неу- } \\
\text { стойки }\end{array}$ \\
\hline 42 & 1 июня 2018 г. & Изменение условий банковской гарантии \\
\hline 43 & 29 июня 2018 г. & $\begin{array}{l}\text { Изменение сферы регулирования закона касательно унитарных предприятий, } \\
\text { автономных учреждений }\end{array}$ \\
\hline 44 & 1 июля 2018 г. & $\begin{array}{l}\text { Появление новых электронных способов закупок, изменение порядка элек- } \\
\text { тронного документооборота, добавление нового единого требования, изме- } \\
\text { нения порядка и размера обеспечения заявок, обязанность указания страны } \\
\text { происхождения товара в составе заявки, только при применении националь- } \\
\text { ного режима, появление возможности взимать плату за победу в электронной } \\
\text { процедуре, изменение срок рассмотрения первых частей заявок в электронном } \\
\text { аукционе, изменение шага аукциона, изменение порядка заключения контрак- } \\
\text { та в электронных процедурах }\end{array}$ \\
\hline
\end{tabular}




\begin{tabular}{|c|c|c|}
\hline 45 & 30 июля 2018 г. & $\begin{array}{l}\text { Изменение оснований закупки у единственного поставщика (подрядчика, } \\
\text { исполнителя) }\end{array}$ \\
\hline 46 & 31 июля 2018 г. & Изменение сферы регулирования закона \\
\hline 47 & 14 августа 2018 г. & $\begin{array}{l}\text { Невозможность более устанавливать критерии оценки заявок и величины их } \\
\text { значимости при проведении запроса предложений, не предусмотренные зако- } \\
\text { ном }\end{array}$ \\
\hline 48 & 11 ноября 2018 г. & $\begin{array}{l}\text { Изменение оснований закупки у единственного поставщика (подрядчика, } \\
\text { исполнителя) }\end{array}$ \\
\hline 49 & 27 декабря 2018 г. & $\begin{array}{l}\text { Изменение порядка обеспечения заявок, добавление нового основания закупки } \\
\text { у единственного поставщика (подрядчика, исполнителя) }\end{array}$ \\
\hline 50 & 1 января 2019 г. & $\begin{array}{l}\text { Добавление основания проведения запроса предложений, введение порядка } \\
\text { регистрации в единой информационной системе, изменение правил закупки у } \\
\text { субъектов малого предпринимательства и социально ориентированных НКО }\end{array}$ \\
\hline 51 & 7 января 2019 г. & Изменение порядка проведения экспертизы при исполнении контракта \\
\hline 52 & 28 марта 2019 г. & $\begin{array}{l}\text { Изменение оснований закупки у единственного поставщика (подрядчика, } \\
\text { исполнителя) }\end{array}$ \\
\hline 53 & 1 мая 2019 г. & $\begin{array}{l}\text { Запрет закупки услуг по организации отдыха детей и их оздоровления элек- } \\
\text { тронным аукционом }\end{array}$ \\
\hline 54 & 12 мая 2019 г. & $\begin{array}{l}\text { Изменение порядка начисления штрафов и пеней, сокращение сроков обжало- } \\
\text { вания закупки }\end{array}$ \\
\hline 55 & 27 июня 2019 г. & $\begin{array}{l}\text { Уточнение правил обоснования НМЦК, изменение условий исполнения кон- } \\
\text { трактов по строительству и реконструкции }\end{array}$ \\
\hline 56 & 1 июля 2019 г. & $\begin{array}{l}\text { Введение реестра документов, подтверждающих соответствие дополнитель- } \\
\text { ным требованиям, изменение правил проведения электронного аукциона при } \\
\text { закупке строительства, реконструкции капитального ремонта в соответствии } \\
\text { с проектной документацией, введение гарантийных обязательства, изменение } \\
\text { сроков проведения электронного аукциона, изменение сроков рассмотрения } \\
\text { первых частей заявок, изменение даты и шага аукциона, изменение оснований } \\
\text { закупки у единственного поставщика (подрядчика, исполнителя), добавление } \\
\text { условия изменения контракта, изменение условий обеспечения исполнения } \\
\text { контракта }\end{array}$ \\
\hline 57 & 8 июля 2019 г. & $\begin{array}{l}\text { Изменения осуществления закупки товара, производство которого создается } \\
\text { или модернизируется (осваивается) на территории РФ в соответствии со СПИК }\end{array}$ \\
\hline 58 & 31 июля 2019 г. & $\begin{array}{l}\text { Изменение правил закупки бюджетными учреждениями, изменение оснований } \\
\text { и правил закупки у единственного поставщика (подрядчика, исполнителя) }\end{array}$ \\
\hline 59 & 1 октября 2019 & $\begin{array}{l}\text { Изменения в порядке планирования закупок: отмена планов-закупок, изме- } \\
\text { нения требований к планам-графикам, изменение требований к содержанию } \\
\text { извещения о закупке }\end{array}$ \\
\hline 60 & 28 декабря 2019 г. & Изменение условий банковской гарантии \\
\hline 61 & 1 января 2020 г. & $\begin{array}{l}\text { Страна происхождения товара в составе заявки указывается не только при } \\
\text { применении национального режима, изменения в порядке контроля в сфере } \\
\text { закупок }\end{array}$ \\
\hline 62 & 8 января 2020 г. & $\begin{array}{l}\text { Возможность заключения контракт жизненного цикла в случае, закупок новых } \\
\text { машин и оборудования }\end{array}$ \\
\hline
\end{tabular}

Составлена авторами в процессе исследования

\section{Библиографический список}

1. Алексеев А.Н., Гришина Н.К. Системный подход к совершенствованию государственных закупок // Транспортное дело России. 2019. № 2. С. 21-23.

2. Бижоев Б. М. Основы интеллектуальной контрактной системы в сфере государственных закупок // JOURNAL OF ECONOMIC REGULATION (Вопросы регулирования экономики). 2018. Т. 9. № 1. С. 110-122.

3. Зюзгина К. А., Паулов П.А. Государственные закупки: современные проблемы // Бюллетень науки и практики. 2018. Т. 4. № 12. С. 493-497. Режим доступа: http://www.bulletennauki.com/12-27. (Дата обращения 15.12.2019). 
4. Официальный сайт Министерства финансов Российской Фежерации. Сводный аналитический отчет по результатам осуществления мониторинга закупок, товаров, услуг для обеспечения государственных и муниципальных нужд в соответствии с Федеральным законом от 05.04.2013 № 44-Ф3 «О контрактной системе в сфере закупок товаров, работ, услуг для обеспечения государственных и муниципальных нужд» по итогам 2018 года // Режим доступа: https://www.minfin.ru/common/upload/library/2019/04/main/Svodnyy_ analiticheskiy_otchet_2018_itog.docx (Дата обращения 15.12.2019).

5. Официальный сайт «Финмаркет». Уровень потерь в госзакупках вырос на 60,7\% - эксперты. Режим доступа: http://www.finmarket.ru/news/5137037. (Дата обращения 17.12.2019).

6. Официальный сайт «Финмаркет». Минфин сократит число подзаконных актов к закону о госзакупках. Режим доступа: http://www.finmarket.ru/news/5018668. (Дата обращения 17.12.2019).

7. Шмелева M.В. Предотвращение коррупции и других злоупотреблений в сфере государственных закупок // Российское право: образование. практика. Наука. 2018. № 1. С. 5-12. 